\title{
EDITORIAL
}

\section{El Convenio Marco para el Control del Tabaco}

E 121 de mayo fue aprobado el Convenio Marco para el Control del Tabaco (CMCT). Que en los momentos actuales un problema de relevancia internacional se haya abordado en rondas de negociaciones ya lo hace de por sí un documento emblemático; sin embargo, este documento también pasará a la historia por ser el primer tratado multilateral iniciado por la Asamblea Mundial de la Salud, cuerpo que gobierna la Organización Mundial de la Salud (OMS). Esencialmente se trata de una convocatoria a la cooperación basada en la suficiente evidencia científica sobre los daños que el tabaco causa a la salud. La magnitud de este logro quedó bien definida por la Directora General de la OMS, doctora Gro Harlem Brundtland, quien expresó que este Convenio "...es un parte aguas en la colaboración internacional en un mundo globalizado. Esto significa que las naciones estarán trabajando juntas sistemáticamente para proteger la vida de las generaciones presentes y futuras, y tomando responsabilidades compartidas para hacer del mundo un lugar mejor y más sano".

Tras casi cuatro años de debates se presenta este documento, cuyo objetivo es la protección de las personas contra las devastadoras consecuencias sanitarias, sociales, ambientales y económicas del tabaco, dando un marco para las medidas de control que habrán de aplicarse a escala nacional, regional e internacional con el fin de reducir de manera continua y sustancial la prevalencia del consumo y la exposición al humo de tabaco (Artículo 3).

Los principios básicos que sostienen este convenio son siete: a) todos deben estar informados sobre las consecuencias sanitarias, la naturaleza adictiva y la amenaza mortal del consumo y exposición al humo de tabaco; b) se requiere un compromiso político firme para establecer y respaldar medidas multisectoriales integrales y respuestas coordinadas; c) cooperación internacional, particularmente la transferencia de tecnologías, conocimientos y asistencia financiera; d) pre- venir la incidencia de las enfermedades, la discapacidad y la mortalidad prematura causadas por el tabaco; e) ocuparse de la responsabilidad, penal y civil, inclusive la compensación cuando proceda; f) asistencia técnica y financiera para aquellos cuyos medios de vida se afecten por los programas de control del tabaco, y g) la participación de la sociedad civil es esencial para conseguir el objetivo del Convenio y de sus protocolos.

Las medidas que establece el CMCT son esencialmente de dos tipos. Las primeras están relacionadas con la reducción de la demanda. En este sentido el Artículo 6 es explícito en recomendar el aumento de los impuestos y para ello cada Parte deberá considerar sus propios objetivos de salud. Igualmente, se desalienta la venta de productos de tabaco libres de impuestos. Los no fumadores deberán ser protegidos en sus lugares de trabajo, transporte público y lugares públicos cerrados (Artículo 8). Los productos de tabaco deben ser regulados en su contenido. Asimismo, se debe revelar al público información relativa a los componentes tóxicos de los productos de tabaco y sus emisiones (Artículos 9 y 10).

También se requieren etiquetas sanitarias cubriendo al menos $30 \%$ de las superficies principales de los paquetes de cigarros y eventualmente cubrirán $50 \%$. Los mensajes deberán ser rotativos y pueden incluir fotografías o esquemas explicativos. Igualmente, se prohibe el uso de términos engañosos para el consumidor como suaves o ligeros (light) o bajo en alquitrán (Artículo 11), y en correspondencia con lo anterior se promueve la educación, comunicación, formación y concienciación del público (Artículo 12).

El Artículo 13 comienza con el reconocimiento de que sólo la prohibición completa de la publicidad, la promoción y el patrocinio reducirían el consumo de tabaco. No obstante, este artículo, valiente por su contenido, es uno de los más débiles para su ejecución, pues cada Parte adoptará las medidas en un plazo de cinco 
años a partir de la entrada en vigor del Convenio, e inclusive se prevé que algunos países sólo harán restricciones sin llegar a la prohibición total de la publicidad. La última de este primer grupo de medidas se refiere a que los países procurarán incluir servicios para el abandono de la dependencia del tabaco en sus programas nacionales de salud (Artículo 14).

El segundo tipo son las medidas orientadas a la reducción de la oferta de tabaco. En este sentido, se requieren acciones para eliminar el contrabando de tabaco (Artículo 15), como el hecho de que cada paquete exhiba los datos de origen y destino, así como su estatus legal. Una de las medidas más efectivas, pero a la vez de las más frecuentemente violadas hasta ahora, es la prohibición de venta a menores de edad, y la distribución gratuita o sin control de productos del tabaco (Artículo 16). Igualmente, se tiene previsto promover alternativas económicamente viables para los trabajadores, cultivadores y, eventualmente, los pequeños vendedores de tabaco (Artículo 17).

Adicionalmente, entre los aspectos más destacados se recomiendan la acción legal, la cooperación técnica y científica, y la comunicación de información. El Artículo 19 acuerda considerar medidas legislativas y de litigación para lograr el control del tabaco; mientras que el Artículo 20 es el que más de cerca involucra a los centros de investigación, instándolos a promover programas nacionales, regionales e internacionales y a establecer sistemas de vigilancia epidemiológica.

Las Partes se han comprometido a promover mundialmente la financiación del control del tabaco. Para lo anterior se deja abierta la posibilidad de movilizar asistencia económica de todas las fuentes disponibles. Igualmente, se estimula a las instituciones financieras y para el desarrollo a que consideren el control del tabaco entre sus temas prioritarios (Artículo 26).

Acompañando al reconocimiento generalizado del CMCT también se le ha señalado que la búsqueda de consensos debilitó su contenido. En este sentido, varias agrupaciones e individuos reclaman por qué en los temas en donde había una abrumadora mayoría que respaldaba ciertas propuestas se hicieron concesiones suavizando los términos, o eliminando puntos críticos, para lograr la aprobación de unos pocos Estados económicamente muy fuertes, y claramente vinculados a los intereses de las grandes transnacionales del tabaco. Asimismo, se señala como una limitación esencial la imposibilidad de lograr la prohibición completa de la publicidad desde el mismo momento de entrada en vigor del Convenio.

México, como país que aprobó este Convenio y que esperamos pronto lo ratifique para transformarlo en una fuerza real, entra en una nueva etapa donde ha aceptado el compromiso de reforzar la legislación nacional para el control del tabaco. Es cierto que en nuestro país los pasos para combatir al tabaco, y reducir su impacto negativo en la salud se habían iniciado antes de que se aprobara este documento, pero igualmente cierto es que existe la necesidad de profundizar las acciones emprendidas, y sobre todo velar por su cumplimiento.

Establecer una política fiscal más estricta, la prohibición total de la publicidad, la observancia del mínimo de edad legalmente establecido para adquirir productos de tabaco y hacer efectivas las recomendaciones sobre el etiquetado son los principales temas pendientes, y su reforzamiento estaría en plena concordancia con lo planteado en el Artículo 2.1 del $\mathrm{CMCT}^{*}$ "...se alienta a las Partes a que apliquen medidas que vayan más allá de las estipuladas en el presente Convenio y sus protocolos, y nada en estos instrumentos impedirá que una Parte imponga exigencias más estrictas que sean compatibles con sus disposiciones y conformes al derecho internacional".

Maestro Raydel Valdés Salgado

\footnotetext{
* El texto completo del Convenio Marco para el Control del Tabaco se puede consultar en: http://www.who.int/gb/fctc/PDF/inb6/einb65.pdf.

‡ Departamento de Investigación sobre Tabaco, Instituto Nacional de Salud Pública.
} 